\title{
ANÁLISE DA EXPRESSÃO DO COLÁGENO VI NA DISTROFIA MUSCULAR CONGÊNITA
}

\author{
Regina Toni Loureiro de Freitas' ${ }^{1}$ Edmar Zanoteli², \\ Maria da Penha Ananias Morita ${ }^{3}$, Acary Souza Bulle Oliveira ${ }^{4}$
}

\begin{abstract}
RESUMO - A distrofia muscular congênita (DMC) compõe um grupo de miopatias caracterizadas por hipotonia e fraqueza muscular notadas já no primeiro ano de vida. A forma de Ullrich é caracterizada por retrações musculares proximais e hiperextensibilidade distal. Cerca de $40 \%$ destes pacientes apresentam mutações em um dos genes que codificam as três sub-unidades do colágeno VI (COL6), acarretando deficiência total ou parcial na marcação da proteína. Analisamos, através de imunofluorescência, a marcação do COL6 em fragmentos musculares de 50 pacientes com DMC, 20 deles com ausência da marcação para merosina. Identificamos 4 casos com deficiência total da marcação do COL6 (8\% do total), representando 13\% dos casos com marcação normal para merosina. As alterações histológicas musculares dos pacientes com COL6 deficiente eram indistinguíveis das outras formas de DMC, porém mais brandas que as observadas na DMC com deficiência de merosina. Em três dos pacientes com COL6 deficiente observou-se hipotonia e fraqueza muscular, notadas já no período neonatal, atraso do desenvolvimento motor, retrações musculares em joelhos e cotovelos, hiperextensibilidade distal e luxação congênita do quadril (dois pacientes). Um paciente perdeu a capacidade para a marcha, e outro faleceu por problemas respiratórios. A análise da marcação do COL6, assim como da merosina, no tecido muscular de pacientes com DMC pode auxiliar na identificação e caracterização fenotípica dos diversos subtipos de DMC.
\end{abstract}

PALAVRAS-CHAVE: colágeno tipo VI, distrofia muscular congênita, imunofluorescência.

\begin{abstract}
Analysis of the expression of collagen $\mathrm{VI}$ in congenital muscular dystrophy
ABSTRACT - Congenital muscular dystrophy (CMD) composes a group of disorders characterized by hypotonia and muscular weakness noticed in the first year of life. The Ullrich's form is characterized by proximal joint contractures and distal hiperextensibility. About $40 \%$ of these patients present mutations in one of the genes that codify the sub-units of the collagen VI protein (COL6), producing total or partial deficiency of the protein expression. We analyzed, through immunohistochemistry, the expression of COL6 in muscle fragments of 50 patients with CMD; 20 of them presented merosin expression deficiency. We identified 4 cases with total COL6 deficiency ( $8 \%$ of the total), representing $13 \%$ of the cases with normal merosin expression. The histological findings of patients with deficiency of COL6 were indistinguishable from other forms of CMD, but milder than that abnormalities observed in merosin deficient patients. In three COL6 deficient patients were observed hypotonia and weakness in the neonatal period, delayed of motor milestones, muscular retractions of knees and elbows, distal joint hiperextensibility and congenital hip dislocation (two patients). One patient lost the ability to walk; and one died due to respiratory problems. The analysis of COL6 expression, as well as merosin expression, in the muscle tissue from CMD patients, can be important for identification and phenotypic characterization of different CMD subtypes.
\end{abstract}

KEY WORDS: type VI collagen, congenital muscular dystrophy, immunohistochemistry.

A distrofia muscular congênita (DMC) compõe um grupo de miopatias caracterizadas clinicamente por hipotonia e fraqueza muscular notadas no primeiro ano de vida, e histologicamente por alterações distróficas do tecido muscular esquelético ${ }^{1,2}$. Algumas formas manifestam comprometimento as- sociado ao sistema nervoso central (SNC) e anomalias oculares ${ }^{1,2}$. Vários genes estão envolvidos nesta síndrome ${ }^{2,3}$. Quase a metade dos casos é causada por mutações no gene da cadeia $\beta^{2}$ da laminina-2, chamada de merosina, uma proteína da matriz extracelular que se relaciona com as proteínas intra-

\footnotetext{
Disciplina de Neurologia da Universidade Federal de São Paulo, Escola Paulista de Medicina São Paulo SP, Brasil, (UNIFESP-EPM) e Serviço de Doenças Neuromusculares e Eletroneuromiografia (Departamento de Ciências Neurológicas) da Faculdade de Medicina de São José do Rio Preto (MPAM), Brasil: ${ }^{1}$ Bióloga, Mestre em Ciências pela UNIFESP-EPM; ${ }^{2}$ Neurologista, Doutor em Medicina pela UNIFESP-EPM; ${ }^{3}$ Neurologista, Mestre em Neurologia pela UNIFESP-EPM; ${ }^{4}$ Neurologista, Doutor em Medicina pela UNIFESP-EPM, Chefe do Setor de Investigação em Doenças Neuromusculares (UNIFESP-EPM)
}

Recebido 19 Agosto 2004, recebido na forma final 17 Novembro 2004. Aceito 17 Janeiro 2005.

Dra. Regina Toni - Disciplina de Neurologia / UNIFESP - Rua Botucatu 840 - 04023-900 São Paulo SP - Brasil. E-mail: reginatoni@uol.com.br 
citoplasmáticas, como a distrofina, através de interações com o complexo distroglicano na membrana da fibra muscular ${ }^{2,4}$. Outras formas mais raras de DMC são causadas pela deficiência genética de diversas proteínas, tais como o colágeno $\mathrm{VI}$ [genes COL6A1 e COL6A2 (21q22) e COL6A3 (2q37)] (DMC forma de Ullrich); integrina $\beta 7$ (gene ITGA7, 12q); selenoproteína-N1 (gene SPT1, 1p35) (DMC com espinha rígida); fukutina-relacionada (gene FKRP, 19q1) (DM C1C); proteína "acetilglucosaminiltransferase-like" (gene LARGE, 22q) (DMC1D); fukutina (gene Fukutin, 9q31) (doença de Fukuyama); O-manose $\beta$ 1,2-N-acetilglucosamiltransferase (gene POMGnT1, 1p33) (DMC forma músculo-olho-cérebro) e O-mannosyltransferase 1 (gene POMT1, 9q34) (síndrome de Walker-Warburg) ${ }^{2,3,5}$. Existe, ainda, um grupo heterogêneo de pacientes com DMC, cujo defeito genético, ou a deficiência protéica, ainda não foram identificados. Estes pacientes são incluídos no subgrupo chamado de DMC com merosina presente (DMC-MP) ${ }^{2,6}$.

A DMC forma de Ullrich, descrita em $1930^{7}$, é c aracterizada clinicamente por retrações articulares proximais dos membros, hiperextensibilidade das articulações distais e fraqueza e atrofia muscular difusa ${ }^{1,2,7,8}$. Em cerca de $40 \%$ dos pacientes com fenótipo de Ullrich têm sido identificadas mutações em um dos genes que codificam as três sub-unidades do colágeno VI (COL6) ${ }^{9-14}$, acarretando deficiência parcial ou total da expressão desta proteína. O COL6 é composto pelas subunidades $\beta 1, \beta 2$ e $\beta 3$, codificadas respectivamente pelos genes COL6A1, COL6A2, COL6A3 $3^{15,16}$. A análise da marcação do COL6 no tecido muscular de crianças com DMC, assim como a análise da merosina, torna-se importante no sentido de classificar estas crianças em subtipos clinicamente mais homogêneos, auxiliando na caracterização fenotípica.

O objetivo deste estudo foi o de detectar dentro de uma casuística de 50 pacientes com diagnóstico de DMC, aqueles com deficiência na marcação da proteína COL6 no músculo esquelético; e apresentar o quadro clínico e histológico destes pacientes.

\section{MÉTODO}

Pacientes - Foram analisados 50 fragmentos de biopsia muscular de pacientes com diagnóstico de DMC, estocados em freezer a $-85^{\circ} \mathrm{C}$, no Setor de Doenças Neuromusculares (DNM) da UNIFESP-EPM, no período de janeiro de 1995 a dezembro de 2003. Haviam sido excluídos previamente seis casos: quatro casos que não possuíam fragmentos musculares estocados suficientes; um paciente com diagnóstico molecular de DMC forma de Fukuyama ${ }^{17}$ e um caso com quadro clínico de DMC forma músculo-olho-cérebro. Como controle foram analisados também fragmentos musculares considerados $n$ o rmais $(n=5)$ e distróficos de causas diversas (cinco com diagnóstico de distrofia muscular de Duchenne e cinco com diagnóstico de distrofia muscular de cinturas). Este estudo foi avaliado e aprovado pelo Conselho de Ética Médica do Hospital São Paulo.

Os critérios utilizados para o diagnóstico da DMC foram $^{1,18}$ : hipotonia e fraqueza muscular manifestandose até o primeiro ano de vida; tecido muscular com aspecto distrófico, caracterizado por variabilidade no tamanho das fibras, alteração da arquitetura interna das fibras, proliferação do tecido conjuntivo endomisial e perimisial, porém, com ausência de anormalidades estruturais específicas (corpos nemalínicos, centralização nuclear, "core" central, mini-multi "cores", "ragged-red fibers", entre outras).

Técnica - A biopsia muscular foi realizada no músculo deltóide. Os fragmentos musculares foram rapidamente congelados em nitrogênio líquido e, posteriormente, submetidos a colorações de hematoxilina e eosina (HE), tricrômio de Gomori modificado (GO), ácido periódico de Schiff (PAS) e "oil red" O (ORO); e reações histoquímicas de NADH-tetrazolium redutase, succinato desidrogenase (SDH), adenosina trifosfatase (ATPase) em diferentes $\mathrm{pHs}$ $\left(4,3 ; 4,6\right.$ e 9,4), conforme metodologia bem estabelecida ${ }^{18}$.

O estudo foi realizado no Setor de DNM da UNIFESPEPM utilizando-se a técnica de imunofluorescência indireta ${ }^{19}$. Foram empregados anticorpos primários contra as proteínas colágeno $\mathrm{VI}$ (clone $5 \mathrm{C} 6$, monoclonal antimouse, development studies Hybridoma Bank, título 1:400); m e rosina ( $\beta 2$ chain laminin, anti-mouse monoclonal, 300 kDa, Novocastra, título 1:100), distrofina (Dystrophins C/N/R, Dys C/N/R, anti-mouse monoclonais, Novocastra, título 1:20) e adalina (alfa-sarcoglican, anti-mouse monoclonal, Novocastra, título 1:100). Como anticorpo secundário foi utilizado o FITC anti-mouse (Sigma, título 1:100).

As lâminas foram analisadas conjuntamente por dois especialistas na área de histologia muscular (EZ, ASBO), em microscópio de epifluorecência da marca Olympus 60-X.

\section{RESULTADOS}

Em fragmentos musculares controles, considerados normais e naqueles distróficos, observamos uma $m$ a rcação homogênea para o COL6 nos espaços endomisial e perimisial, realçando o sarcolema das fibras musculares, sem falhas de marcação (Fig 1A).

Dentre os 50 casos de DMC incluídos no estudo, em 20 havia ausência de marcação para a merosina (DMC com deficiência de merosina), e em 4 foi constatada deficiência total na marcação do COL6 (8\%) (Fig 1B), os quais re $\mathrm{p}$ resentavam cerca de $13 \%$ dos casos com marcação normal para a merosina. Nenhum caso apresentou deficiência parcial da mar- 


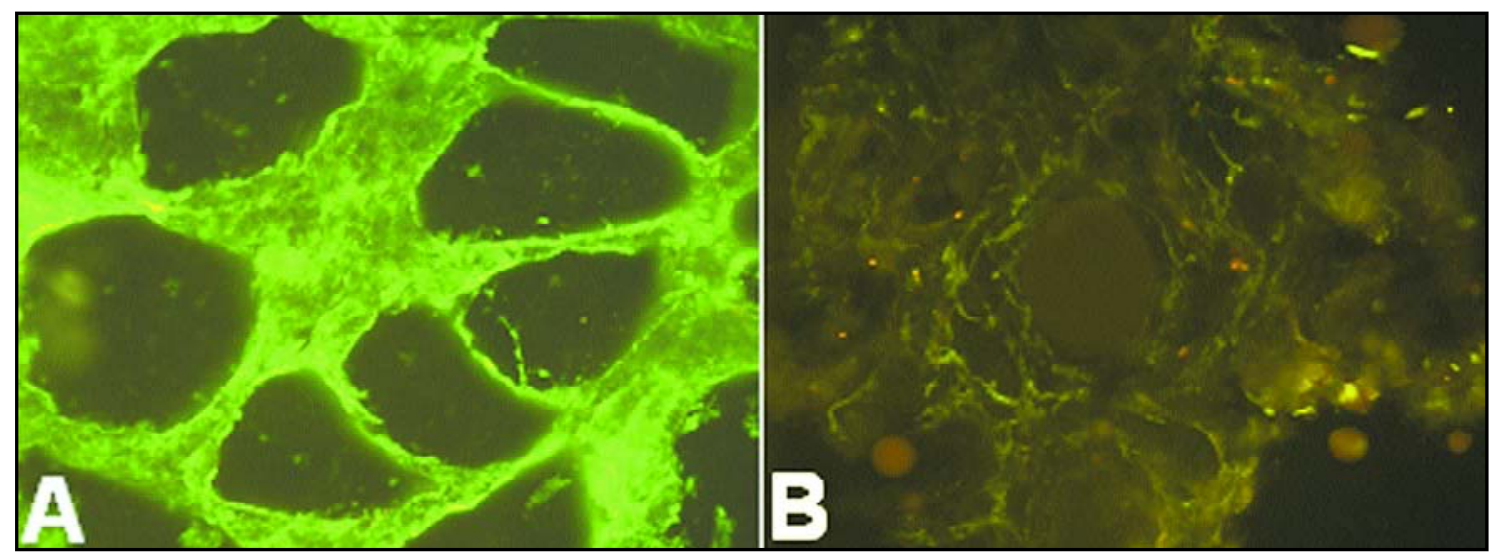

Fig 1. Expressão do Colágeno VI (COL6) no tecido muscular esquelético (imunofluorescência). A) Marcação normal para o COL6. B) Ausência total da expressão do COL6 (caso 3).

Tabela. Aspectos clínicos gerais em 3 crianças com deficiência do colágenoVI.

\begin{tabular}{|c|c|c|c|}
\hline Caso & 1 & 2 & 3 \\
\hline Sexo & $\mathrm{F}$ & $\mathrm{F}$ & M \\
\hline Idade na $1^{\text {a }}$ avaliação & $3 a 4 m$ & $11 a$ & $6 a$ \\
\hline Idade na biopsia & $3 a 7 m$ & $12 a$ & $6 a 8 m$ \\
\hline Hipotonia neonatal & + & + & + \\
\hline Atraso motor & + & + & + \\
\hline Início da marcha & $2 a 3 m$ & $3 a 6 m$ & $2 \mathrm{a} 6 \mathrm{~m}$ \\
\hline Capacidade para marcha & + & - & + \\
\hline Fraqueza muscular & difusa & difusa & difusa \\
\hline Hipotonia/arreflexia & + & + & + \\
\hline Retração muscular & joelhos & Cotovelos, calcâneos & Cotovelos e joelhos \\
\hline Frouxidão ligamentar distal & NA & NA & + \\
\hline Outros & Luxação congênita do quadril & Pé torto congênito & Luxação congênita do quadril \\
\hline Consangüinidade & - & + & + \\
\hline ENMG & NA & miopático & miopático \\
\hline CK & NA & $\mathrm{NI}$ & $1,5 \times$ \\
\hline
\end{tabular}

a, anos; m, meses; F, feminino; $M$, masculino; NA, não avaliado; NI, normal; +, presente; -, ausente; ENMG, eletroneuromiografia; $C K$, creatinoquinase.

cação do COL6. Mesmo naqueles casos com deficiência da merosina, a marcação do COL6 foi normal. A marcação das proteínas distrofina e adalina foi normal em todos os casos.

\section{Descrição histológica dos casos com deficiência} do COL6 - Os principais achados histológicos dos quatrocasos com deficiência do COL6 foram variabilidade moderada no tamanho das fibras, presença de fibras atrofiadas e arredondadas, com aumento moderado ou intenso de tecido conjuntivo endomisial e perimisial. Fibras em necrose e macrofa gia foram raramente observadas. Em todos havia predominância de fibras do tipo 1 e o aspecto em mosaico estava pre s e rvado. $A$ arquitetura interna das fibras encontrava-se alterada de forma leve a moderada, com a presença de fibras em mordida de traça e turbilhonamento. Tais achados não nos permitiam diferenciar estes casos dentre outros da nossa casuística de DMC. No entanto, observamos que as alterações encontradas eram menos proeminentes que aquelas observadas na DMC com deficiência de merosina.

Descrição clínica dos casos com deficiência do COL 6 - Dos 4 casos com deficiência do COL6, obtivemos informações clínicas objetivas de apenas três deles, as quais estão apresentadas na Tabela. O nível cognitivo era normal em todos os casos. $O$ paciente 2 evoluiu para óbito aos 14 anos de idade devido à pneumonia e pneumotórax. Um paciente (caso 2) perdeu a marcha posteriormente devido a procedimento cirúrgico para correção de deformidades nos pés. 


\section{DISCUSSÃO}

Em um total de 50 pacientes com diagnóstico clínico e histológico de DMC, encontramos 4 com deficiência total na marcação do COL6 no tecido muscular ( $8 \%$ dos casos), os quais representavam ce rca de $13 \%$ dos pacientes com marcação normal para a merosina. Em nenhum caso observamos marcação parcial do COL6, especialmente naqueles com merosina negativa. Alguns pesquisadores têm demonstrado a dificuldade em caracterizar os casos com deficiência parcial do COL6 ${ }^{12}$. Nestes casos, usualmente, há redução da marcação no sarcolema e marcação normal no interstício' ${ }^{12}$. Assim, uma forma utilizada nestes estudos para auxiliar no diagnóstico de déficit parcial do COL6 é a realização conjunta da análise da marcação de outras proteínas que marcam a lâmina basal, tais como o COL4 e o perlecan ${ }^{12}$, os quais não foram realizados em nosso estudo. A literatura mostra que cerca de $40 \%$ dos pacientes com DMC e fenótipo de Ullrich apre se ntam deficiência parcial ou total do COL6 ${ }^{11}$. Mesmo os pacientes confirmados com estudo de ligação ou por detecção de mutações nos genes do COL6 podem apresentar marcação normal da proteína no tecido muscular ${ }^{12}$. Além do mais, alguns pacientes com DMC e fenótipo de Ullrich podem manifestar expressão normal do COL6 e ausência de ligação genética nos genes do COL6, indicando uma heterogeneidade neste grupo de pacientes ${ }^{12}$. Com estes dados podemos concluir que, no momento, é difícil determinar com segurança a porcentagem de pacientes com fenótipo de Ullrich que são causados por mutações nos genes do COL612. Em nossa casuística de DMC havia alguns pacientes com fenótipo de Ullrich, mas cuja marcação do COL6 foi normal (dados não apresentados). Estes casos são, certamente, candidatos para estudos genéticos futuro $s$. Um aprimoramento na técnica de imunohistoquímica, utilizando anticorpos mais sensíveis para o COL6, certamente auxiliará na distinção dos casos com deficiência parcial.

Como pudemos observar, a deficiência do COL6 não afeta a marcação de outras proteínas, tais como merosina, distrofina e adalina. Tal achado sugere que em parte a lâmina basal (merosina) se mantém preservada, como já havia sido apontado previamente por Ishikawa et al. ${ }^{20}$. Esses autores sugerem que a perda da conexão entre a lâmina basal e o interstício, devido à ausência de microfibrilas, seria um importante mecanismo no desenvolvimento de distrofia muscular nestes pacientes ${ }^{20}$.
Nos três casos em que tivemos a oportunidade de obter informações clínicas, constatamos que o fenótipo era bem homogêneo, com o início da doença ocorrendo no período neonatal e com atraso das aquisições motoras, mas com aquisição da marcha. Um paciente perdeu a marcha posteriormente devido a procedimento cirúrgico para correção de deformidades nos pés. Na literatura têm-se observado que as crianças com deficiência do COL6, inclusive com confirmação genética, apresentam um fenótipo caracterizado por fraqueza muscular generalizada, retrações musculares proximais, hiperextensibilidade articular distal e cognição normal. No entanto, tem-se observado variabilidade quanto ao grau do comprometimento motor e a evolução da doença. Ou seja, enquanto alguns adquirem a capacidade para a marcha, a maioria nunca chega a deambular ${ }^{14}$. Alguns autores têm demonstrado que aqueles casos com um fenótipo mais leve, especialmente quanto à presença da marcha, apresentam deficiência apenas parcial do COL6 na biopsia muscular ${ }^{11,14}$.

Apesar de muitos pacientes com DMC por deficiência de COL6 apresentarem um fenótipo mais brando, o envolvimento respiratório pode se tornar altamente incapacitante e levar ao óbito precocemente, como pudemos observar em um dos nossos $\operatorname{casos}^{11,14}$. Ao lado da fraqueza da musculatura respiratória, as deformidades da coluna vertebral também favorecem a um pior prognóstico ${ }^{11}$. A p resença de hiperextensibilidade distal tem sido obse nada em praticamente todos os casos publicados de DMC com fenótipo de Ullrich e deficiência do COL6. Embora possa ser observada também na miopatia de Bethlem e na DMC com espinha rígida, alguns autores consideram a hiperextensidade distal como o achado clínico mais específico para a DMC com deficiência do $\mathrm{COL}^{14}$. Outro achado freqüentemente descrito é a deslocação congênita do quadril, observado em um dos nossos casos, o qual parece estar também relacionada com a hiperextensibilidade articular ${ }^{14}$.

Não tem sido descrito envolvimento do SNC, clinicamente ou através de exames de imagem, em pacientes com o fenótipo de Ullrich ${ }^{11,14}$. Os nossos três casos tinham, aparentemente, cognição preservada, sem relatos de convulsões. Alterações ao exame de sensibilidade, equilíbrio e cerebelar não são freqüentes nestes casos.

Assim como pudemos detectar nos nossos pacientes, os achados histológicos do tecido muscular esquelético são inespecíficos, sendo caracterizados 
por variabilidade no tamanho das fibras, fibras a trofiadas arredondadas e aumento variável de tecido conjuntivo endomisial e perimisial ${ }^{11,14}$. Raramente têm sido descritas fibras em necrose ou em regeneração. Eventualmente, há predomínio de fibras do tipo 1, mas com o aspecto em mosaico presenvado. A arquitetura interna das fibras encontra-se alterada de forma leve a moderada ${ }^{11,14}$. Tais achados $h$ istológicos são similares, mas bem menos exuberantes, que aqueles observados na DMC com deficiência da merosina. No entanto, não é possível a distinção da DMC com deficiência do COL6 das outras formas de DMC, através da análise histológica convencional de rotina e histoquímica.

Em conclusão, dentre aqueles pacientes com DMC com merosina normal, uma porcentagem ainda não definida claramente, apresenta deficiência da proteína COL6. Estes pacientes apresentam o clássico fenótipo da síndrome de Ullrich. No entanto, nem todos os pacientes com o fenótipo de Ullrich são causados por deficiência do COL6, indicando heterogeneidade. Estudos futuros, utilizando análise molecular e anticorpos mais sensíveis contra - COL6, serão fundamentais para melhor caracterizar estes casos.

Agradecimentos - Agradecemos a Prof. Dra Rita de Cássia Sinigaglia Galli Coimbra pelo apoio científico na execução do trabalho, e a Sra Marlene Silveira Rocha pelo auxílio laboratorial.

\section{REFERÊNCIAS}

1. Tomé FMS, Guicheney P, Fardeau M. Congenital muscular dystrophies. In Emery AEH (ed). Neuromuscular disorders: clinical and molecular genetics. Chichester: John Wiley \& Sons, 1998:21-58.

2. Mercuri E, Sewry C, Brown SC, Muntoni F. Congenital muscular dystrophies. Semin Pediatr Neurol 2002;9:120-131.

3. Muntoni F, Valero de Bernabe B, Bittner R, et al. 114th ENMC International Workshop on Congenital Muscular Dystrophy (CMD) 17-19
January 2003, Naarden, The Netherlands: (8th Workshop of the International Consortium on CMD; 3rd Workshop of the MYO-CLUSTER project GENRE). Neuromusc Disord 2003;13:579-588.

4. Fardeau M, Tome FM, Helbling-Leclerc A, et al. Congenital muscular dystrophy with merosin deficiency: clinical, histopathological, immunocytochemical and genetic analysis. Rev Neurol (Paris) 1996;152:11-19.

5. Weil D, Mattei MG, Passage E, et al. Cloning and chromosomal localization of human genes encoding the three chains of type VI collagen. Am J Hum Genet 1988;42:435-445.

6. Fukuyama Y. Congenital muscular dystropies: an update. J Child Neurol 1999;14:28-30.

7. Ullrich O. Kongenitale, atonisch-sklerotische Muskeldystrophie, ein weiterer Typus der heredodegenerativen Erkrankungen des neuromuskulären Systems. Z Ges Neurol Psychiatr 1930;126:171-201.

8. Nonaka I, Une Y, Ishihara T, Miyoshino S, Nakashima T, Sugita H. A clinical and histological study of Ullrich's disease (congenital atonic atonic-sclerotic muscular dystrophy). Neuropedriatrics 1981;12:197-208.

9. Camacho-Vanegas O, Bertini E, Zhang RZ, et al. Ullrich scleroatonic muscular dystrophy is caused by recessive mutations in collagen type VI. Proc Natl Acad Sci USA 2001; 98:7516-7521.

10. Higuchi I, Shiraishi T, Hashiguchi T, et al. Frameshift mutation in the collagen VI gene causes Ullrich's disease. Ann Neurol 2001;50:261-265.

11. Mercuri E, Yuva Y, Brown SC, et al. Collagen VI involvement in Ullrich sy nd rome a clinical, genetic, and immunohistochemical study. Neurology 2002;58:1354-1359.

12. Pepe G, Bertini E, Bonaldo P, et al. Bethlem myopathy and Ullrich scleroatonic muscular dystrophy: 100th ENMC International Workshop. 23-24 November 2001, Naarden, The Netherlands. Neuromusc Disord 2002;12:984-993.

13. Pan TC, Zang RZ, Sudano DG, Marie SK, Bönnemann CG, Chu ML New molecular mechanism for Ullrich congenital muscular dystrophy: a heterozygous in-frame deletion in the COL6A1 gene causes a severe phenotype. Am J Hum Genet 2003;73:355-369.

14. Demir E, Ferreiro A, Sabatelli P, et al. Collagen VI status and clinical severity in Ullrich congenital muscular dystrophy: phenotype analysis of 11 families linked to the COL6 Loci. Neuropediatrics 2004;35:103-112.

15. Engel J, Furthmayr H, Odermatt E, et al. Structureand macromolecular organization of type VI collagen. Ann NY Acad Sci 1985;460:25-37.

16. Chu ML, Pan TC, Conway D, et al. The structure of type VI collagen. Ann NY Acad Sci 1990;580:55-63.

17. Zanoteli E, Rocha JC, Narumia LK, et al. Fukuyama-type congenital muscular dystrophy: a case report in the Japanese population living in Brazil. Acta Neurol Scand 2002;106:117-121.

18. Dubowitz V. Muscle disorders in childhood, 2nd ed. London: WB Saunders, 1985.

19. Vainzof M, Zubrzycka-Gaarn EE, Rapaport D, et al. Immunofluorescence dystrophin study in Duchenne dystrophy through the concomitant use of two antibodies directed against the carboxy-terminal and the amino-terminal region of the protein. J Neurol Sci 1991;101:141-147.

20. Ishikawa H, Sugie K, Murayama K, et al. Ullrich disease: collagen VI deficiency: EM suggests a new basis for muscular weakness. Neurology 2002;59:920-923. 